\title{
Advancements in functionality and quality characteristic of yoghurt- a fermented dairy product: a review
}

\author{
Riar, H. ${ }^{1}$, Goel, N. ${ }^{2}{ }^{凶}$
}

Received: 30.09.2020

Revised: 13.12.2020

Accepted: 18.12.2020

\begin{abstract}
Yoghurt a fermented product is a wholesome, nutritious food product, liked by every segment of the population. There has been a continuous effort in increasing the quality of the product by fortification and technological interventions. Researchers have focused on the addition of vitamins and minerals to eradicate micronutrient deficiency as well as the addition of health-promoting bioactive functional ingredients such as Hibiscus sabdariffa (calyx) extract and natural antimicrobial agents such as essential oils to increase the shelf life and quality parameters of yoghurt. In the case of lowfat yoghurt, carbohydrate-based fat replacers like barley beta-glucan, guar gum and inulin were used and compared with milk fat. Present review focuses on the influence of antioxidant-rich fruits such as Rutub date, mulberry pekmez and concentrated grape juice on the fermentation and quality of fruit flavoured yoghurt. There has been an innovation in product design such as carbonated yoghurt prepared from sweetened low-fat yoghurt and yog-ice cream by addition of inulin. The present review signifies that enrichment of yoghurt with functional ingredients leads to enhancement in the quality, storage stability as well as health benefits making it a product suitable for maintaining good health and curing diseases of the population in a whole.
\end{abstract}

Key Words: Antioxidants, micronutrients, natural bioactive ingredients, rheological stability, vitamins, yoghurt

\section{Introduction}

A Fermented dairy product like yoghurt is a rich source of nutrients, for example, riboflavin (Vitamin $\mathrm{B}_{2}$ ), thiamine (Vitamin $\mathrm{B}_{1}$ ) and Vitamin $\mathrm{B}_{12}$. It contains a decent measure of macronutrients, for example, the protein which is of high biological value and minerals like calcium, phosphorous, magnesium and zinc that are effectively bioavailable for the human body. It is of utmost significance for lactose intolerance consumers as it is hard for them to digest lactose because of insufficiency of the enzyme, i.e. $\beta$-galactosidase (lactase). Therefore, they show symptoms such as flatulence, diarrhoea and abdominal pain. Researchers have reported that consumption of yoghurt provides health benefits such as a decrease in risk of disease, (Heyman 2000) for example, hypertension (Takano 1998, Taylor and Williams 1998), bringing down of cancer growth (Van't et al., 1989), maintenance of gastrointestinal microflora and control of diarrhoea

\footnotetext{
Author's Address

${ }^{1}$ Punjab Milk Cooperative Federation (Verka), Chandigarh, India

${ }^{2}$ College of Dairy Science and technology, Guru Angad Dev Veterinary and Animal Sciences University, Ludhiana, Punjab, E-mail.: nitika.gadvasu@gmail.com
}

(Boudraa et al., 1990). These health benefits have been possible because of improved lactose absorption as the lactose gets converted into lactic acid (Vesa et al., 1996) and henceforth disposal of lactose indigestion symptoms. The beneficial microorganisms present in yoghurt such as Lactobacillus delbrueckii bulgaricus and Streptococcus thermophilus exist in a complex cooperative relationship in which one bacterium produces stimulatory agents for the other. $L$. bulgaricus produces certain amino acids such as valine, leucine and histidine which are essential for $S$. thermophilus to grow. These amino acids are produced as a result of proteolysis of casein by $L$. bulgaricus (Marranzini et al., 1989; Abu-tarboush, 1996). S. thermophilus, in turn, encourages the growth of $L$. bulgaricus by producing formic acid and carbon dioxide (Matalon and Sandine, 1986). These volatile compounds provide yoghurt with the characteristics flavour (Routray et al., 2011). The soft and thicker texture of yoghurt as compared to its milk is because of production of exopolysaccharides (EPS) as viscosifying agent generated by these lactic acid bacteria (LAB) (Yang et al., 2014). These LAB possess preservative 


\section{Riar and Goel}

properties release antimicrobial metabolites known as bacteriocins, which have great potential to be used in food preservation (Zacharof et al., 2012). The worldwide pattern in the yoghurt production in recent years as presented by the International Dairy Federation (IDF, 2016) is portrayed in Figure 1. It is demonstrated that there was over $10 \%$ expansion in the purchase from 2010 to 2015 in nations, for example, United States, Canada, Mexico, Chile, Norway, Sweden, South Africa, Zimbabwe, China and Japan. Different nations, for example, Australia, Denmark and Germany additionally announced a $5-10 \%$ expansion in the purchase. A few nations even show a decrease in the purchase worth, for example, Argentina, France and Israel and this might be because of the internal issues of the nations, for example, poor economy, change in the legislative strategies and decrease in the currency value. In general, it showed that yoghurt and other dairy items would grow in their utilisation throughout the following decade. In India, likewise, the yoghurt market developed at a compound yearly development rate (CAGR) of $28.9 \%$ during 2011-2015, and it is projected to touch US\$1 Billion by the end of 2021.

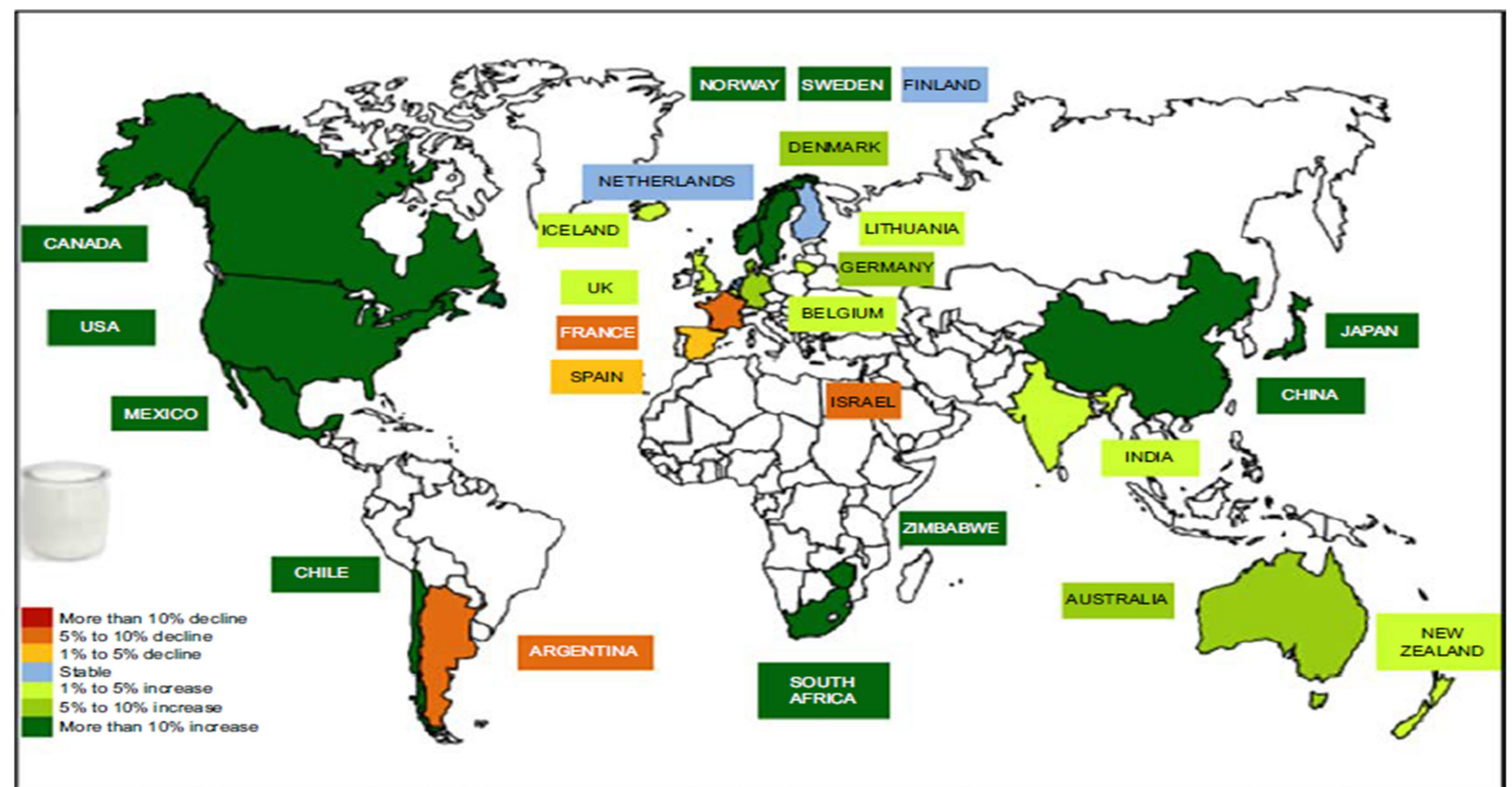

Figure 1. Global Trends in yoghurt purchase and sale value from 2010 to 2015 (International Dairy Federation, 2016)

\section{Vitamin and Mineral Fortification}

Fortification of yoghurt with nutrients and minerals is the best approach to alleviate vitamin and mineral deficiency by utilisation of our ordinary everyday diet. Vitamin D deficiency is predominant everywhere in the world because of a greater amount of indoor working hours, leading to less exposure to sun and consequently predominance of deficiency. To control this issue, Jafari et al. (2016) studied the stability of Vitamin $\mathrm{D}_{3}$ in fortified yoghurt as well as in yoghurt drink called Doogh. They showed that the treatments such as pasteurisation, homogenisation and fermentation had no critical impact on Vitamin D stability.
Vitamin D was prepared in two forms, i.e. oil dispersible and water dispersible, and it was seen that both these were stable during the storage of yoghurt when stored in dark containers. The waterdispersible Vitamin D fortified yoghurt was not stable in the clear containers, and thus its stability decreases, following 3 weeks of storage while the oil dispersible form kept in similar containers was likewise stable for a week and significantly diminished following 2-3 weeks of storage. Vitamin $\mathrm{D}_{3}$ retention was additionally studied and examined by Kazmi et al. (2007) in yoghurt when stored at $4^{\circ} \mathrm{C}$. It was accounted for the loss of 0.1 $0.2 \%$ of Vitamin $\mathrm{D}$ in yoghurt. 
Research on the addition of Vitamin $\mathrm{A}$ and $\mathrm{C}$ to plain and raspberry flavoured low-fat yoghurt was examined by Ilic et al. (1988). The yoghurt samples prepared were kept at refrigeration temperature for about a month and a half for storage study, and they were examined two times in seven days. The observations indicated that the nutrient level diminished steadily with Vitamin $\mathrm{C}$ diminishing at a lot quicker rate in contrast with Vitamin A. In any case, it was seen that $100 \%$ US RDA prerequisite of Vitamin $\mathrm{A}$ and $\mathrm{C}$ was recovered even after 6week analysis. It was likewise revealed that the addition of Vitamins had no critical impact on the $\mathrm{pH}$, titratable acidity and the sensory attributes of the yoghurt.

The probiotic culture greatly affects the healthenhancing elements of the yoghurt and impact of the addition of $\mathrm{B}$ complex Vitamins, for example, Vitamin $\mathrm{B}_{1}$ (thiamine), Vitamin $\mathrm{B}_{2}$ (riboflavin), pyridoxine, pyridoxal, pyridoxamine and folic acids were studied by Papastoyiannidis et al. (2006). During the research, observations were done where vitamins were $50 \%$ lost, i.e. during the heating of the milk and fermentation, but vitamins stay stable during storage for 16 days at refrigeration temperature. Species and strain of the culture had an impact on the vitamin level all through the fermentation and storage study of the product. This fortification level applied to the fermented dairy product is a decent option in contrast to dietary enhancements as they are effectively absorbed, and it adds to the advantageous impact of probiotics microorganisms as well as the vitamins included. Additionally, the impact of the incorporation of Folic acid on the qualities of yoghurt was reported by Aryana (2003). The folic acid was added in two distinct stages and furthermore at two unique concentration levels for example during mix preparation (before pasteurisation) at $25 \% \mathrm{RDA}$ value and following culture addition (after pasteurisation) at 50\% RDA value of Folic acid. It was seen that the overall sensory attributes of the yoghurt demonstrated a yellowish tone when contrasted with the control samples. The folic acid fortified yoghurt had fundamentally lower flavour, body and texture scores but had better water holding capacity when compared with the control samples. There was no impact on the $\mathrm{pH}$ and titratable acidity of the folic acid fortified yoghurt. The determination of proper delivery framework to enhance the bioavailability of the fundamental nutrients, for example, Vitamin A, D and E with the goal that it adds to human wellbeing by preventing certain disease and improvement of overall health was studied by Öztürk (2017). He studied that lipidbased delivery framework can be utilised to deliver these lipophilic nutrients and subsequently increase their solubility, stability as well as the bioavailability. This lipid-based delivery framework offers an advantage as they can be utilised in fortification of water-based beverage/drink alongside lipid-based formulations. Staple foods and beverages such as orange juice, milk, cheese and bread could be fortified with stable vitamin-enriched nanoemulsions, so human can get profits by these micronutrients. In these oilin-water nanoemulsions, there is an oil phase where the lipophilic bioactive compound is the present and aqueous phase where there is an amphiphilic interfacial layer which is made out of emulsifier to enhance the strength of the nanoemulsion prepared. The nanoemulsions are prepared both by low energy and high energy techniques, is a promising delivery framework to stabilise lipophilic vitamins during the food fortification and hence improve their bioavailability.

Adding functionality to yoghurt to enhance the rheology and structural stability

The structural and rheological attributes of yoghurt could be improved by the addition of proteins, for example, whey protein isolate. For these, two different kinds of yoghurt were prepared, low protein and high protein yoghurt. It was seen that the higher protein version of yoghurt appeared to diminish more craving when contrasted with the lower protein form of yoghurt (Vadewater et al., 1996). The study was also done in which non-fat yoghurt was prepared to utilise skim milk which was braced with higher milk protein powder up to $5.6 \%$. The additional protein helped with giving all the firmer body and insignificant whey separation without any use of stabiliser (Mistry et al., 1992). The addition of whey protein isolate leads to viscosity lowering effect as observed by Patocka et al. (2006). The whey protein isolate was added in two stages, i.e. before fermentation (BF) and after fermentation (AF) of the unfortified yoghurt. It was seen that the before Fermentation yoghurt has the same characteristics as commercial yoghurt, but after fermentation yoghurt showed more whey 51 
separation and a decrease in the overall sensory score of the product. Similarly, the impact of the addition of whey protein isolate on the general sensory qualities of yoghurt was examined by Guggisberg et al. (2007). They observed the consistency and microstructural properties of the yoghurt. The whey protein isolate included was in the range of $3-12 \%$, and it was added before the fermentation process. The consistency and rheological qualities were studied utilising two principle techniques: resistance to penetration by a cylinder and oscillating system. It was seen that both these techniques demonstrated incredible outcomes which were equivalent to one another. The rheological, textural and sensory qualities of low-fat yoghurt were additionally examined when carbohydrate-based fat replacers were added such as barley beta-glucan $(0.5 \%)$, partially hydrolysed guar gum and inulin (at a higher rate, for example, $2 \%$ ) by Brennan et al. (2008). It was accounted that by addition of these carbohydrate-based fat replacers, it led to a decrease in whey syneresis and the overall structural characteristics of the low-fat yoghurt compared with that of full-fat yoghurt.

There have been advancements in the product design with the addition of inulin to improve the general textural scores of the yog-ice cream desserts. This leads to an increase in the consistency of ice cream yoghurt mix and the hardness of the yog-ice cream prepared. The melting down qualities of yog-ice cream were accounted for by El-Nagar et al. (2002), and it was seen that there is a reasonable connection between increased oligosaccharide level and melting attributes of ice-cream. Another advancement wherein carbonation was fused to the improved low fat yoghurt in specific varieties such as plain, strawberry and lemon which was prepared by utilising cream, non-fat dry milk, sugar, stabiliser and skim milk. The yoghurt culture was added and incubated at controlled temperature conditions until the ideal $\mathrm{pH}$ is attained. Carbon dioxide was added into the cooled, flavoured yoghurt at a rate of 0.08 to $0.09 \mathrm{~kg} / \mathrm{cm} 2$ utilising sterile hose pipe. The yoghurt prepared was stored at $4^{\circ} \mathrm{C}$, and the sensory evaluation was done by the team at 7,21 and 45 days. Karagül-Yüceer et al. (1999) saw that carbonation has no critical impact on the overall acceptability and sensory properties of yoghurt.

\section{Addition of health promoting functional ingredients in yoghurt}

Researchers have focussed on the addition of health-promoting bioactive functional ingredients like Hibiscus sabdariffa (calyx). It has been reported that Hibiscus sabdariffa (calyx) acts a potential source of bioactive agents that possesses antioxidant-antiradical activity, anti-obesity, antiinflammatory action, anti-hypertensive, antimicrobial and prevent the risk of cancer (Moyano et al., 2016). Iwalokun et al. (2007) studied the impact of the addition of Hibiscus on the physicochemical qualities of the yoghurt. It was seen that there was a decline in the coagulation time. However, it was also observed that there was a decrease in the overall acceptability as well as the sensory score value of the yoghurt in which Hibiscus was added.

The addition of natural antimicrobial agents such as essential oils to fortified yoghurt and its impact on the physicochemical, sensory and health-promoting functions was studied by Otaibi et al. (2008). These oils have antimicrobial properties (Burt, 2004), and these properties have been attributed due to phenols and polypeptides (Ismail et al., 2006). These essential oils are also used as food flavouring agents or preservatives (El-Nawawy et al., 1998). The essential oils included were thyme, marjoram and sage added at a concentration of $0.2,0.5$ and $1.0 \mathrm{ppm}$. On observing the chemical and microbiological properties, it was seen that it affected the $\mathrm{pH}$, soluble and total nitrogen content. However, at a concentration of $0.2 \mathrm{ppm}$, it was discovered to be organoleptically acceptable and lead to an increase in the shelf life of the product up to 21 days. A study was conducted to increase the natural antioxidant content in yoghurt by addition of rutub dates by Ismail (2019). The observations included the physicochemical, microbial and organoleptic properties of the yoghurt prepared. Observations demonstrated that there was an acceleration in the fermentation rate and decline in coagulation time. The rheological characteristics depicted that there was a decline in the curd syneresis and increase in curd tension, viscosity and water holding capacity of the yoghurt prepared. The addition of dates leads to an increase in the mineral and total nitrogen content. There was a positive effect on the viability of lactic acid microbes and bifidobacteria, and consequently, more probiotic 
impact on the yoghurt prepared when contrasted with the control samples. Similarly, fruit yoghurt was prepared by utilising concentrated grape juice to milk by Öztürk et al. (1999). It was seen that the addition of $10 \%$ grape juice gives the ideal sweetness as well as an increase in the fermentation time and decrease in the viscosity of yoghurt. During the storage study, it was observed that acidity of concentrated grape juice yoghurt was lower than the control samples. Further, the fruit flavoured yoghurt was likewise prepared utilising mulberry pekmez into the milk by Celik et al. (2003). The mulberry pekmez added had more content of minerals such as calcium, sodium, magnesium, phosphorus and Iron, which enhanced the nutritional value of the product. The diverse concentration of mulberry pekmez was selected i.e. $2.5,5.0,7.5$ and $10 \%$. It was seen that by addition of mulberry pekmez into yoghurt leads to

\section{References}

Abu tarboush H.M. 1996. Comparison of associative growth and proteolytic activity of yoghurt starter in whole milk from camelsand cows. Journal of Dairy Science. 79:366371.

Aryana, K. J. 2003. Folic acid fortified fat free plain set yoghurt. International Journal of Dairy Technology, 56(4): 219-22.

Boudraa, G., Touhami, M., Pochart, P., Soltana, R., Mary, J. Y. and Desjeux, J. F. 1990. Effect of feeding yoghurt versus milk in children with persistent diarrhea. Journal of Pediatric Gastroenterology and Nutrition, 11: 509-12.

Brennan, C. S. and Tudorica, C. M. 2008. Carbohydrate based fat replacers in the modification of the rheological, textural and sensory quality of yoghurt: comparative study of the utilisation of barley beta-glucan, guar gum and inulin. International journal of food science \& technology, 43(5): 824-833.

Burt, S. 2004. Essential oils: their antibacterial properties and potential applications in foods. International Journal of Food Microbiology, 94: 223-253.

Celik, S. and Bakirci, I. 2003. Some properties of yoghurt produced by adding mulberry pekmez (concentrated juice). International Journal of Dairy Technology, 56(1): 26-29.

El-Nagar, G., Clowes, G., Tudorică, C. M., Kuri, V. and Brennan, C. S. 2002. Rheological quality and stability of yog-ice cream with added inulin. International Journal of Dairy Technology, 55(2): 89-93. an increase in the fermentation time and a decrease in the viscosity of yoghurt prepared. During the storage study, it was observed that there was more whey separation when compared with control samples, although the acidity, consistency and the lactic acid bacterial count was lower than the control samples.

\section{Conclusion}

Yoghurt is a well-known and healthy dairy product which is an indispensable part of the human diet. Subsequently, fortification of yoghurt with essential bioactive functional ingredients is an extraordinary way to deal with the eradication of deficiency and to enhance the nourishment by consuming a cup of yoghurt. Since a ton of usefulness can be added to this healthy dairy product, so its fortification has an excellent research perspective.

El-Nawawy, M. A., El-Kenany, Y. M. and Abd El-Ghaffar, E. A. 1998. Effect of some herb plants on the use of yoghurt culture. Annals of agriculture Sci. 7 th . Conf. Agric. Dev. Res. Fac. Agric. Ain Shams University of Cairo, Egypt, 15-17.

Guggisberg, D., Eberhard, P. and Albrecht, B. 2007. Rheological characterization of set yoghurt produced with additives of native whey proteins. International Dairy Journal, 17(11): 1353-59.

Heyman, M. 2000. Effect of lactic acid bacteria on diarrheal diseases. Journal of American College of Nutrition, 19: 137-46.

Ilic, D. B. and Ashnoor, S. H. 1988. Stability of Vitamins A and $\mathrm{C}$ in Fortified Yoghurt. Journal of Dairy Science, 71: 1492-98.

Ismail, M. M. 2019.Improvement of nutritional and healthy values of yoghurt by fortification with rutub date. Journal of Microbiology, Biotechnology and Food Sciences, 398406.

Ismail, A. M., Harby, S. and Salem, A. S. 2006. Production of flavored labneh with extended shelf life. Egyptian Journal of Dairy Science, 34: 59-68.

Iwalokun, B. A. and Shittu, M. O. 2007. Effect of Hibiscus sabdariffa (calyce) extract on biochemical and organoleptic properties of yoghurt. Pakistan Journal of Nutrition, 6(2): 172-182.

Jafari, T., Askari, G., Mirlohi, M., Javanmard, S. H., Faghihimani, E. and Fallah, A. A. 2016. Stability of 
Vitamin D3 in fortified yoghurt and yoghurt drink (Doogh). Advanced biomedical research, 5.

Karagül-Yüceer, Y., Coggins, P. C., Wilson, J. C. and White, C. H. 1999. Carbonated yoghurt-sensory properties and consumer acceptance. Journal of dairy science, 82(7): 1394-1398.

Kazmi, S. A, Vieth, R. and Rousseau, D. 2007. Vitamin D3 fortification and quantification in processed dairy products. International Dairy Journal, 17: 753-59.

Moyano, G., Sáyago-Ayerdi, S. G., Largo, C., Caz, V., Santamaria, M., and Tabernero, M. 2016. Potential use of dietary fibre from Hibiscus sabdariffa and Agave tequilana in obesity management. Journal of Functional Foods, 21: $1-9$.

Mistry, V. V. and Hassan, H. N. 1992. Manufacture of nonfat yoghurt from a high milk protein powder. Journal of dairy science, 75(4): 947-57.

Marranzini, R. M., Schmidt, R. H., Shireman, R. B., Marshall, M. R. and Cornell, J. A. 1989. Effect of theronine and glycine concentrations on threonine aldolase activity of yoghurt microorganisms during growth in a modified milk prepared by ultrafiltration. Journal of Dairy Science, 6: $87-112$.

Matalon, M. E. and Sandine, W. E. 1986. Lactobacillus bulgaricus, Streptococcus thermophilus and yoghurt. $\boldsymbol{A}$ review of Cultured Dairy Product Journal, 21: 6-12.

Otaibi, M. A. and Demerdash, H. E. 2008. Improvement of the quality and shelf life of concentrated yoghurt (labneh) by the addition of some essential oils. African Journal of Microbiology Research, 2(7): 156-161.

Ozturk, B. 2017. Nanoemulsions for food fortification with lipophilic vitamins: Production challenges, stability, and bioavailability. European Journal of Lipid Science and Technology, 119(7): 510-39.

Öztürk, B. A. and Öner, M. D. 1999. Production and evaluation of yoghurt with concentrated grape juice. Journal of Food Science, 64(3): 530-532.
Papastoyiannidis, G., Polychroniadou, A., Michaelidou, A. M. and Alichanidis, E. 2006. "Fermented milks fortified with B-group vitamins: vitamin stability and effect on resulting products. Food science and technology International, 12(6): 521-29.

Patocka, G., Cervenkova, R., Narine, S. and Jelen, P. 2006. Rheological behaviour of dairy products as affected by soluble whey protein isolate. International dairy journal, 16(5): 399-405.

Routray, W. and Mishra, H. N. 2011. Scientific and Technical Aspects of Yoghurt Aroma and Taste: A Review. Comprehensive Reviews in Food Science and Food Safety, 10(4): 208-220.

Takano, T. 1998. Milk derived peptides and hypertension reduction. International Dairy Journal, 8: 375-81.

Taylor, G .R. J. and Williams, C. M. 1998. Effects of probiotics and prebiotics on blood lipids. British Journal of Nutrition, 80: 225-30.

Vadewater, K. and Vickers, Z. 1996. Higher protein foods produce greater sensory specific satiety. Physiology and Behavior, 59(3): 579-83.

Van't, V. P., Dekker, J. M., Lamers, J. W., Kok, F. J., Schouten, E. G., Brants, H. A. and Hermus, R J. 1989. Consumption of fermented milk products and breast cancer: a case-control study in The Netherlands. Cancer research, 49(14): 4020-23.

Vesa, T. H., Marteau, P. H., Zidi, S., Briet, F. S., Pochart, P. H. and Rambaud, J. C. 1996. Digestion and tolerance of lactose from yoghurt and different semi-solid fermented dairy products containing Lactobacillus acidophilus and Bifidobacteria in lactose maldigesters-Is bacterial lactase important. European Journal of Clinical Nutrition, 50: $730-33$

Yang, T. X., Wu, K. Y., Wang, F. X., Liang, L., Liu, Q. S., G, Li, and Li, Q. Y. 2014. Effect of Exopolysaccharides from Lactic Acid Bacteria on the Texture and Microstructure of Buffalo Yoghurt, International Dairy Journal, 34(2): 252256.

Zacharof, M. P. and Lovitt, R. W. 2012. Bacteriocins Produced by Lactic Acid Bacteria, APCBEE Procedia, 2: 50-56. 